\title{
A Renal Size Discrepancy among the Findings of Renal Sonogram in Children with Their First Episode of Pyelonephritis is One of the Useful Parameters to Predict the Presence of Cortical Defects on the Acute DMSA Renal Scan
}

\author{
Yoowon Kwon, M.D. \\ Bo kyeong Jin, M.D. \\ Seonkyeong Rhie, M.D., Ph.D. \\ Jun Ho Lee, M.D., Ph.D. \\ Department of Pediatrics, CHA Bundang \\ Medical Center, CHA University School of \\ Medicine, Seongnam-si, Korea \\ Corresponding author: \\ Jun Ho Lee, M.D, Ph.D. \\ Department of Pediatrics, CHA Bundang \\ Medical Center, CHA University School of \\ Medicine, 351 Yatap-dong, Bundang-gu, \\ Seongnam-si, Gyeonggi-do, 13496, Korea \\ Tel: +82-31-780-5011 \\ Fax: +82-31-780-5011 \\ E-mail:naesusana@gmail.com \\ Co-corresponding author: \\ Seonkyeong Rhie, M.D., Ph.D. \\ Department of Pediatrics, CHA Bundang \\ Medical Center, CHA University School of \\ Medicine, 351 Yatap-dong, Bundang-gu, \\ Seongnam-si, Gyeonggi-do, 13496, Korea \\ Tel: +82-31-780-1864 \\ Fax: +82-31-780-5011 \\ E-mail: naesusana@gmail.com \\ Received: 27 November 2018 \\ Revised: 19 March 2019 \\ Accepted: 26 March 2019
}

This is an open-access article distributed under the terms of the Creative Commons Attribution Non-Commercial License (http:// creativecommons.org/licenses/by-nc/4.0/) which permits unrestricted non-commercial use, distribution, and reproduction in any medium, provided the original work is properly cited.

Copyright ( 2019 The Korean Society of Pediatric Nephrology
Purpose: We investigated whether a renal size discrepancy on a renal sonogram (US) in children with febrile urinary tract infection (UTI) was correlated with the presence of cortical defects on their dimercaptosuccinic acid (DMSA) renal scan. Methods: We examined 911 children who were admitted consecutively to our hospital with their first episode of febrile UTI from March 2001 to September 2014. All enrolled children underwent a US and DMSA scan during admission. According to the US findings, including the renal size discrepancy, data were compared between children with positive and negative DMSA scan results. A positive DMSA scan result was defined as reduced or absent tracer localization and indistinct margins that did not deform the renal contour.

Results: Mean renal lengths of the right and left kidneys were larger in children with positive DMSA scan results than in children with negative DMSA scan results $(63.2 \pm 11.3 \mathrm{~mm}$ vs. $58.4 \pm 7.8 \mathrm{~mm}, P<0.001 ; 64.9 \pm 11.2 \mathrm{~mm}$ vs. $59.9 \pm 7.9 \mathrm{~mm}, P<$ 0.001 ; respectively). A significant difference was observed in both renal lengths between children with positive and negative DMSA scan results $(4.6 \pm 3.8 \mathrm{~mm}$ vs. $3.3 \pm 2.6 \mathrm{~mm}, P<0.001)$. A multiple logistic regression analysis, revealed that a small kidney, cortical thinning, and a renal length discrepancy on US findings were significant factors for predicting the presence of cortical defects on an acute DMSA scan $[P=0.028,95 \%$ confidence interval $(\mathrm{Cl}) 1.054-2.547 ; P=0.004,95 \% \mathrm{Cl}$ $1.354-4.810 ; P<0.001,95 \% \mathrm{Cl} 1.077-1.190$, respectively].

Conclusion: In conclusion, a renal size discrepancy on US findings in children with their first episode of febrile UTI was a helpful tool for predicting the presence of cortical defects on an acute DMSA scan.

Key words: Cortical defect, DMSA renal scan, Pyelonephritis, Renal sonogram, Urinary tract infection

\section{Introduction}

A renal ultrasonogram (US) is necessary in children with their first episode of pyelonephritis because of several congenital anomalies of the kidney and urinary tract, such as obstructive uropathy (hydronephrosis or hydroureter), duplex kidney, ectopic kidney, horseshoe kidney, hypoplastic kidney, cystic 
kidney disease, ureterocele, bladder diverticulum, patent urachus, and stones, that have the risk of recurrent urinary tract infection (UTI) and can be easily detected. Renal size can be measured. A renal abscess, a complication of acute pyelonephritis (APN), can also be detected. US has a high negative predictive value (NPV; 98.2\%) for detecting high grade vesicoureteral reflux (VUR $)^{1)}$.

However, US has low sensitivity (SS) and specificity (SP) for predicting positive dimercaptosuccinic acid (DMSA) scan results and detecting high grade VUR ${ }^{1,2)}$. Therefore, a secondary imaging study is necessary in children with a recurrent febrile UTI or specific condition. Only pyelonephritis with cortical defects on a DMSA renal scan produces acquired renal scarring, and only such recurrent pyelonephritis can lead to chronic renal insufficiency. Patients with pyelitis, which has the same clinical manifestations as pyelonephritis with a negative DMSA scan result, do not develop acquired renal scarring. Therefore, discriminating pyelonephritis is very important among children with the first episode of febrile UTI.

Various reports have indicated a correlation or a lack of a correlation between abnormal US findings and positive acute DMSA scan results. However, no previous study has been investigated the correlation between a renal size discrepancy on US and positive acute DMSA scan results in acute phase.

In the present study, we investigated whether a renal size discrepancy on US in children with a febrile UTI was correlated with the presence of cortical defects on a DMSA renal scans.

\section{Materials and methods}

Among 2,614 children consecutively admitted to our hospital with the diagnosis of UTI (N39.0) from March 2001 to September 2014, 911 with complete data were included in this retrospective study. In total, 320 children who had a UTI episode in the past or who did not satisfy the UTI criteria (defined as follow below) were excluded. A total of 1,138 children who did not undergo US or a DMSA scan during their admission and 245 children who did not have measured renal lengths medical records, or renal sonogram films were also excluded.
UTI was defined as follows: high fever $\geq 38^{\circ} \mathrm{C}$, abnormal urinalysis (pyuria [ $>5$ White blood cells (WBCs) /highpower field] and positive leukocyte esterase results), positive C-reactive protein $(\mathrm{CRP})$ results $(>0.3 \mathrm{mg} / \mathrm{dL})$, lack of another fever focus, and significant bacteriuria. A total of 118 children with a negative urine culture result, but with positive DMSA scan results, were also included in the UTI group. A positive DMSA scan result (cortical defect) was defined as reduced or absent tracer localization and indistinct margins that did not deform the renal contour.

Urine was sampled by collecting a midstream urine specimen in toddlers or in older children and using the clean catch bag method in non-toilet trained children. Significant bacteriuria was defined as the presence of $\geq 10^{5}$ colonyforming units/high-power field of a single-strain isolate. All enrolled children with a UTI underwent US and a DMSA renal scan upon admission.

US was performed by a pediatric radiologist. Abnormal US findings included small kidneys ( $\leq 95 \%$ of the standard deviation of mean age-matched renal size), hydroureter $(\geq$ $4 \mathrm{~mm}$ ), cortical thinning, increased renal parenchymal echogenicity, hydronephrosis (anteroposterior diameter of renal pelvis $\geq 5 \mathrm{~mm}$ ), swelling, bladder wall thickening and no difference between the corticomedullary junctions. Renal lengths were measured as the longest diameter between the upper and lower pole of each kidney.

DMSA scans were performed using the planar technique with a dual-headed Symbia E gamma camera (Siemens, Erlangen, Germany) equipped with a low-energy high-resolution collimator ( $140 \mathrm{KeV}, 20 \%$ symmetric window) and were interpreted by two nuclear medicine consultants. A positive DMSA scan result was defined as reduced or absent tracer localization and indistinct margins that did not deform the renal contour.

Written informed consent was obtained from the parents of all children with a UTI children prior to the DMSA scan. The CHA University Institutional Review Board approved this study, including the consent procedure (CHA IRB No. 2018-07-063).

All data were collected retrospectively and were compared between the children with positive and negative DMSA scan results according to their US findings. 


\section{Statistical analysis}

All variables are presented as mean \pm standard deviation. Continuous variables were analyzed using the Student's t-test. Qualitative variables and correlations were analyzed using Pearson's chi-square test and Pearson's correlation coefficient analysis (two-tailed probability), respectively. Non-parametric variables were analyzed using Spearman's rank correlation coefficient analysis. A multiple logistic regression analysis (MLRA) was conducted to test the ability of a renal size discrepancy on US to predict the presence of cortical defects on a DMSA scan. The areas under the receiver operating characteristic (ROC) curves of relevant factors and the associated levels of significance were evaluated when the value of the state variable was 1 . The statistical analysis was performed using SPSS statistics 22 software (SPSS Inc, Chicago, IL, USA). A $P$-value $\leq 0.05$ was considered significant.

\section{Results}

\section{Comparison of the imaging data between children} with positive and negative DMSA scan results

A total of 911 children (616 males and 295 females) were included; 118 children (27.2\%) with a positive DMSA scan result were diagnosed with culture-negative pyelonephritis. Congenital hypoplastic kidney [relative renal uptake (RRU) $\leq 35 \%$ on DMSA scan] was detected in 17 children (1.9\%).

A total of 434 children had positive DMSA scan results (47.6\%), whereas 477 children had negative DMSA scan results. A significant difference in age ( $12.8 \pm 24.5$ vs. $7.5 \pm 15.3$ months) was observed between the groups, but no difference was observed in the sex ratio. When the older children were diagnosed with their first episode of UTI, more cortical defects were detected on the DMSA scan.

In this study population, mean renal length was larger in left kidneys than in right kidneys $(62.3 \pm 10$ vs. $60.7 \pm 9.9 \mathrm{~mm}$, respectively; $P<0.001)$. The left kidney was larger than the right kidney in 567 children. The mean difference in renal length was $3.9 \pm 3.3 \mathrm{~mm}$.

Mean renal lengths of the right and left kidneys were larger in children with positive DMSA scan results than in children with negative DMSA scan results $(63.2 \pm 11.3$ vs. $58.4 \pm 7.8 \mathrm{~mm}, P<0.001 ; 64.9 \pm 11.2$ vs. $59.9 \pm 7.9 \mathrm{~mm}, P<0.001$; respectively). No difference in the ratio of children with larger left kidneys than right kidney was observed between children with positive and negative DMSA scan results (1.56 vs. $1.72, P=0.07$ ). Significant differences in both renal lengths were observed between children with positive and negative DMSA scan results ( $4.6 \pm 3.8$ vs. $3.3 \pm 2.6 \mathrm{~mm}, P<$ 0.001).

Even after adjusting for age between DMSA scan positive and negative groups, the mean renal lengths of the right and left kidneys were larger in children with positive DMSA scan results than in children with negative DMSA scan results (61.6 \pm 8.7 vs. $58.4 \pm 7.8 \mathrm{~mm}, P<0.001 ; 63.5 \pm 9.3$. vs. $59.9 \pm$ $7.9 \mathrm{~mm}, P<0.001$; respectively). A significant difference was also found in both renal lengths between the age-adjusted groups ( $4.5 \pm 3.8$ vs. $3.3 \pm 2.6 \mathrm{~mm}, P<0.001$ ). This study in cluded 807 infants of less than 12 month-old, 28 children of 13-24 month-old and 76 children of more than 25 monthold. There was no difference of these results between total study population and 76 children of more than 25 monthold, or between total study population and 835 children of less than 24 month-old (Table 1).

\section{Significant correlations between parameters in this study population}

The differences in both renal lengths on US correlated positively with age, cortical thinning, increased parenchymal echogenicity, hydronephrosis (anteroposterior diameter $>15 \mathrm{~mm}$ ), swelling, and positive DMSA scan results $(\mathrm{r}=0.109, P<0.001 ; \mathrm{r}=0.064, P=0.021 ; \mathrm{r}=0.070, P=0.012 ; \mathrm{r}=-$ $0.071, P=0.011 ; \mathrm{r}=0.134, P<0.001 ; \mathrm{r}=0.145, P<0.001$, respec tively).

The presence of cortical defects on the acute DMSA scan correlated positively with age, hydroureter, increased parenchymal echogenicity, swelling, and the difference in both renal lengths $(\mathrm{r}=0.075, P=0.009 ; \mathrm{r}=0.083, P=0.012 ; \mathrm{r}=$ $0.146, P<0.001 ; \mathrm{r}=-0.182, P<0.001 ; \mathrm{r}=0.145, P<0.001$, respec tively).

\section{Incidence and MLRA of abnormal US findings to predict the presence of cortical defects on an acute DMSA scan}

The multiple logistic regression analysis revealed that a small kidney, cortical thinning, and a differences in both renal lengths on US findings were significant factors for 
predicting the presence of cortical defects on the acute DMSA scan $[P=0.028,95 \%$ confidence interval (CI) $1.054-$ 2.547; $P=0.004,95 \%$ CI $1.354-4.810 ; P<0.001,95 \%$ CI 1.077-1.190, respectively] (Table 2).

\section{ROC curves and $95 \% \mathrm{Cl}$ of renal size discrepancy on US to predict the presence of cortical defects on an acute DMSA scan}

The areas of the ROC curves and 95\% CIs of both renal size discrepancies on US significantly predicted the presence of cortical defects on an acute DMSA scan (0.599, 95 \% CI 0.562-1.636, $P<0.001$ ) (Fig. 1).
5. Comparison of the imaging data between children with RRU $>10 \%$ and $R R U \leq 10 \%$ on a DMSA scan

The renal size discrepancies on US were $6.0 \pm 5.1 \mathrm{~mm}$ and $3.7 \pm 3.0 \mathrm{~mm}$, when RRU $>10 \%$ and $R R U \leq 10 \%$ on DMSA scan respectively. A significant positive correlation $(\mathrm{r}=$ $0.21813, P<0.001)$ was detected. Cortical thinning and increased parenchymal echogenicity on US were also correlated positively with the difference of RRU on the DMSA scan $(P<0.001 ; P<0.001$, respectively) (Table 3$)$.

\section{Discussion}

There is no clear agreement about which imaging guide-

Table 1. Comparison of the Imaging Data between Children with Positive and Negative DMSA Scan Results

\begin{tabular}{|c|c|c|c|c|c|}
\hline & DMSA (+) & $\operatorname{DMSA}(+)^{\prime}$ & DMSA (-) & $P$ value & $P$ value \\
\hline N & 434 & 413 & 477 & & \\
\hline Age (months) & $12.8 \pm 24.5$ & $8.2 \pm 12.6$ & $7.5 \pm 15.3$ & $<0.001$ & 0.43 \\
\hline M:F & 293:141 & 289:124 & $323: 154$ & & \\
\hline \multicolumn{6}{|l|}{ Renal size (mm) } \\
\hline Right kidney (RK) & $63.2 \pm 11.3$ & $61.6 \pm 8.7$ & $58.4 \pm 7.8$ & $<0.001$ & $<0.001$ \\
\hline Left kidney (LK) & $64.9 \pm 11.2$ & $63.5 \pm 9.3$ & $59.9 \pm 7.9$ & $<0.001$ & $<0.001$ \\
\hline Size discrepancy ( $\delta)$ & $4.6 \pm 3.8$ & $4.5 \pm 3.8$ & $3.3 \pm 2.6$ & $<0.001$ & $<0.001$ \\
\hline RK>LK (n) & 156 & 144 & 144 & & \\
\hline RK & $67.5 \pm 12.4$ & $64.9 \pm 8.3$ & $60.6 \pm 9.2$ & $<0.001$ & $<0.001$ \\
\hline LK & $63.5 \pm 11.4$ & $61.1 \pm 7.9$ & $57.7 \pm 8.7$ & $<0.001$ & $<0.001$ \\
\hline$\delta$ & $4.0 \pm 3.3$ & $3.8 \pm 3.0$ & $2.9 \pm 2.6$ & 0.002 & 0.01 \\
\hline RK<LK (n) & 264 & 256 & 303 & & \\
\hline RK & $60.6 \pm 9.6$ & $59.7 \pm 8.4$ & $57.3 \pm 7.1$ & $<0.001$ & $<0.001$ \\
\hline LK & $65.7 \pm 10.9$ & $64.9 \pm 9.8$ & $61.1 \pm 7.6$ & $<0.001$ & $<0.001$ \\
\hline$\delta$ & $5.2 \pm 4.0$ & $5.2 \pm 4.0$ & $3.8 \pm 2.5$ & $<0.001$ & $<0.001$ \\
\hline \multirow[t]{2}{*}{$\mathrm{RK}=\mathrm{LK}(\mathrm{n})$} & 14 & 13 & 30 & & \\
\hline & $64.5 \pm 13.2$ & $61.4 \pm 7.3$ & $58.1 \pm 4.8$ & 0.003 & 0.1 \\
\hline \multicolumn{6}{|l|}{ Cortical defects on } \\
\hline RK (n) & 155 & 146 & & & \\
\hline$\delta$ & $4.6 \pm 3.8$ & $4.5 \pm 3.6$ & & & \\
\hline RK & $63.9 \pm 11.8$ & $61.9 \pm 8.4$ & & & \\
\hline LK (n) & 219 & 211 & & & \\
\hline$\delta$ & $4.8 \pm 4.0$ & $4.8 \pm 4.0$ & & & \\
\hline LK & $65.4 \pm 11.4$ & $64.2 \pm 9.7$ & & & \\
\hline Both kidneys ( $n$ ) & 60 & 56 & & & \\
\hline$\delta$ & $3.6 \pm 3.1$ & $3.6 \pm 3.2$ & & & \\
\hline RK & $65.6 \pm 12.3$ & $63.6 \pm 9.7$ & & & \\
\hline LK & $66.8 \pm 12.0$ & $65.0 \pm 9.8$ & & & \\
\hline
\end{tabular}

$P<0.05$, 'age corrected sample. The laboratory examination results are expressed as mean \pm standard deviation. DMSA (+), the existence of cortical defects on DMSA scan.

Abbreviations: DMSA, dimercaptosuccinic acid; N, number of patients. 
Table 2. Incidence and MLRA of Abnormal US Findings to Predict the Presence of Cortical Defects on Acute DMSA Scan

\begin{tabular}{|c|c|c|c|c|c|c|c|c|}
\hline US findings & $\mathrm{N}$ & Sensitivity & Specificity & PPV & NPV & OR & $\mathrm{Cl}$ & $P$ value \\
\hline Small kidney & 2 & $\begin{array}{c}0.46 \% \\
(0.06-1.65)\end{array}$ & $\begin{array}{c}99.79 \% \\
(98.84-99.99)\end{array}$ & $\begin{array}{c}66.67 \% \\
(15.4-95.65)\end{array}$ & $\begin{array}{c}52.42 \% \\
(52.23-52.61)\end{array}$ & 1.638 & $1.054-2.547$ & 0.028 \\
\hline Hydroureter & 89 & $\begin{array}{c}20.51 \% \\
(16.81-24.62)\end{array}$ & $\begin{array}{c}84.07 \% \\
(80.47-87.24)\end{array}$ & $\begin{array}{c}53.94 \% \\
(47.02-60.71)\end{array}$ & $\begin{array}{c}53.75 \% \\
(52.22-55.28)\end{array}$ & 0.144 & $0.012-1.765$ & 0.129 \\
\hline Cortical thinning & 1 & $\begin{array}{c}0.23 \% \\
(0.01-1.28)\end{array}$ & $\begin{array}{c}99.37 \% \\
(98.17-99.87)\end{array}$ & $\begin{array}{c}25.00 \% \\
(3.36-76.15)\end{array}$ & $\begin{array}{c}52.26 \% \\
(52.05-52.47)\end{array}$ & 2.552 & $1.354-4.810$ & 0.004 \\
\hline $\begin{array}{l}\text { Increased parenchymal } \\
\text { echogenicity }\end{array}$ & 51 & $\begin{array}{c}11.75 \% \\
(8.88-15.16)\end{array}$ & $\begin{array}{c}96.44 \% \\
(94.35-97.91)\end{array}$ & $\begin{array}{c}75.00 \% \\
(63.77-83.64)\end{array}$ & $\begin{array}{c}54.57 \% \\
(53.61-55.52)\end{array}$ & 1.095 & $0.710-1.687$ & 0.682 \\
\hline \multicolumn{9}{|l|}{ Hydronephrosis } \\
\hline$A P D \leq 15 \mathrm{~mm}$ & 106 & $\begin{array}{c}24.42 \% \\
(20.45-28.75)\end{array}$ & $\begin{array}{c}76.31 \% \\
(72.23-80.06)\end{array}$ & $\begin{array}{c}48.40 \% \\
(42.68-54.17)\end{array}$ & $\begin{array}{c}52.60 \% \\
(50.77-54.42)\end{array}$ & 0.512 & 0.070-3.739 & 0.509 \\
\hline APD $>15 \mathrm{~mm}$ & 1 & $\begin{array}{c}0.23 \% \\
(0.01-1.28)\end{array}$ & $\begin{array}{c}98.95 \% \\
(97.57-99.66)\end{array}$ & $\begin{array}{c}16.67 \% \\
(2.29-63.03)\end{array}$ & $\begin{array}{c}52.15 \% \\
(51.90-52.41)\end{array}$ & - & - & 0.995 \\
\hline Swelling & 26 & $\begin{array}{c}5.99 \% \\
(3.95-8.65)\end{array}$ & $\begin{array}{c}99.79 \% \\
(98.84-99.99)\end{array}$ & $\begin{array}{c}96.30 \% \\
(77.99-99.48)\end{array}$ & $\begin{array}{c}53.85 \% \\
(53.25-54.44)\end{array}$ & 1.884 & $0.150-23.738$ & 0.624 \\
\hline Bladder wall thickening & 2 & $\begin{array}{c}0.46 \% \\
(0.06-1.65)\end{array}$ & $\begin{array}{c}99.79 \% \\
(98.84-99.99)\end{array}$ & $\begin{array}{c}66.67 \% \\
(15.40-95.65)\end{array}$ & $\begin{array}{c}52.42 \% \\
(52.23-52.61)\end{array}$ & - & - & - \\
\hline $\begin{array}{l}\text { No differentiation } \\
\text { between C-M junction }\end{array}$ & 1 & $\begin{array}{c}0.23 \% \\
(0.01-1.28)\end{array}$ & $\begin{array}{c}100.00 \% \\
(99.23-100.00)\end{array}$ & $100.00 \%$ & $\begin{array}{c}52.42 \% \\
(52.30-52.53)\end{array}$ & 1.260 & $0.801-1.984$ & 0.318 \\
\hline Normal & 230 & $\begin{array}{c}53.00 \% \\
(48.18-57.77)\end{array}$ & $\begin{array}{c}38.78 \% \\
(34.39-43.32)\end{array}$ & $\begin{array}{c}44.06 \% \\
(41.28-46.88)\end{array}$ & $\begin{array}{c}47.56 \% \\
(43.82-51.32)\end{array}$ & & & \\
\hline
\end{tabular}

The laboratory examination results are expressed as mean \pm standard deviation.

Abbreviations: MLRA, multiple logistic regression analysis; DMSA, dimercaptosuccinic acid; N, number of patients; APD, anterioposterior diameter; C-M, corticomedullary; $P<0.05$.

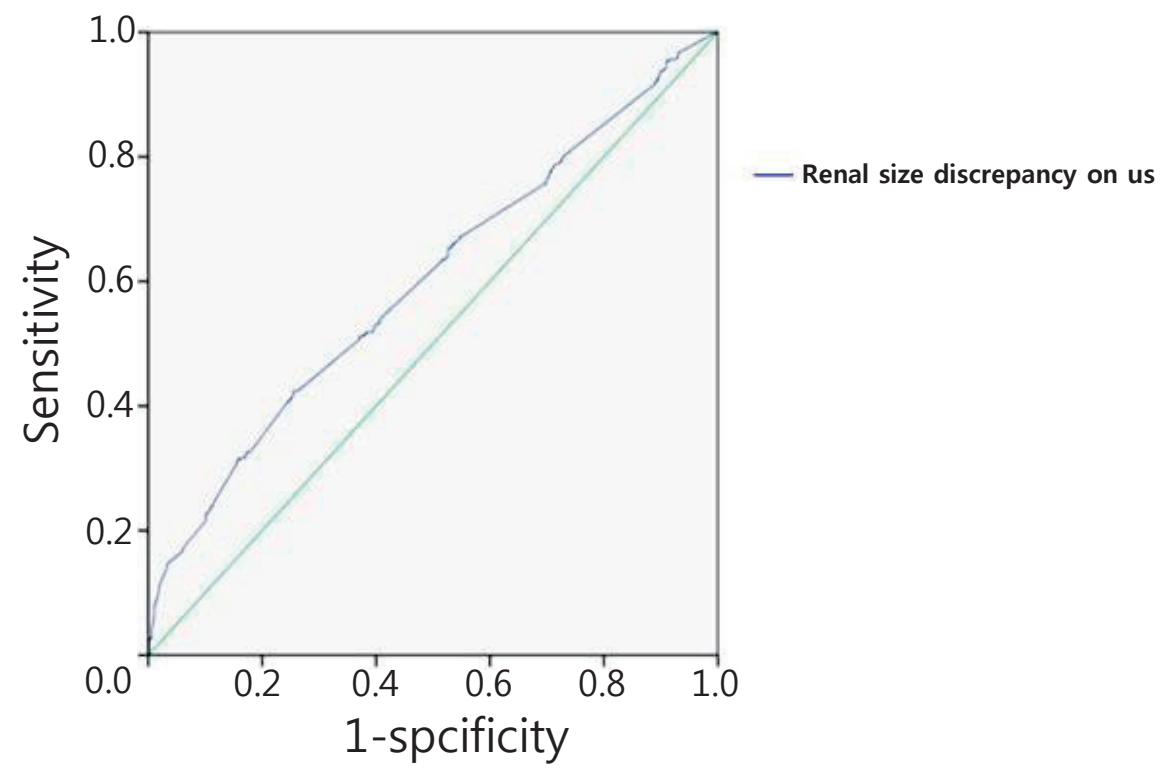

\begin{tabular}{lccc}
\hline $\begin{array}{l}\text { Cortical defects on } \\
\text { Acute DMSA scan }\end{array}$ & AUC & $\boldsymbol{P}$-value & $95 \%$ CI \\
\hline $\begin{array}{l}\text { Both renal size } \\
\text { discrepancy on US }\end{array}$ & 0.599 & $<0.001$ & $0.562-0.636$ \\
\hline
\end{tabular}

AUC, areas under the ROC curve; CI, 95\% confidence interval; $P<0.05$.

Fig. 1. ROC curves and $95 \% \mathrm{CI}$ of renal size discrepancy on US to predict the presence of cortical defects on acute DMSA scan. 
lines in children with their first episode of febrile UTI are desirable considering all aspects of cost, radiation exposure, stress, or the probability of missing high grade VUR or renal scarring. Other authors have maintained our opinion that detecting the presence of congenital or acquired renal scarring in children with a febrile UTI is more important than detecting the presence of high grade VUR for the following reasons. In general, a VUR operation does not have to be performed in very young infants for the first episode of febrile UTI. The VUR operation was not performed on children without renal scarring on their DMSA scan. High grade VUR has a relatively high risk of recurrent UTI and accompanying congenital renal scarring, but all children experiencing recurrent UTI do not have high grade VUR and, moreover, severe congenital renal scarring is not commonly detected ${ }^{1}$. Missing the renal scarring is worse for renal outcome than missing high grade VUR. Furthermore,

Table 3. Comparison of the Imaging Data between Children with RRU $>10 \%$ and RRU $\leq 10 \%$ on a DMSA Scan

\begin{tabular}{|c|c|c|c|}
\hline & $\triangle \mathrm{RRU}>10 \%$ & $\triangle \mathrm{RRU} \leq 10 \%$ & $P$ value \\
\hline $\mathrm{N}$ & 90 & 821 & \\
\hline Age (months) & $15.2 \pm 25.1$ & $9.4 \pm 19.7$ & 0.010 \\
\hline$M: F$ & $53: 37$ & $563: 258$ & \\
\hline \multicolumn{4}{|l|}{ Renal size (mm) } \\
\hline Right kidney (RK) & $64.4 \pm 12.9$ & $60.2 \pm 9.5$ & $<0.001$ \\
\hline Left kidney (LK) & $65.2 \pm 12.7$ & $61.9 \pm 9.6$ & 0.003 \\
\hline Size discrepancy & $6.0 \pm 5.1$ & $3.7 \pm 3.0$ & $<0.001$ \\
\hline DMSA (+) (n) & 73 & 361 & \\
\hline DMSA (-) (n) & 17 & 460 & \\
\hline Small kidney & $1(1.1 \%)$ & $2(0.2 \%)$ & \\
\hline Hydroureter & $19(21.1 \%)$ & $145(17.7 \%)$ & 0.532 \\
\hline Cortical thinning & $3(3.3 \%)$ & $1(0.1 \%)$ & $<0.001$ \\
\hline $\begin{array}{l}\text { Increased parenchymal } \\
\text { echogenicity }\end{array}$ & $21(23.3 \%)$ & $47(5.7 \%)$ & $<0.001$ \\
\hline \multicolumn{4}{|l|}{ Hydronephrosis } \\
\hline \multicolumn{4}{|l|}{$\mathrm{APD} \leq 15 \mathrm{~mm}$} \\
\hline APD $>15 \mathrm{~mm}$ & 33 (36.7\%) & $186(22.7 \%)$ & 0.019 \\
\hline Swelling & $2(2.2 \%)$ & $4(0.5 \%)$ & 0.050 \\
\hline Bladder wall thickening & $9(10.0 \%)$ & $18(2.2 \%)$ & 0.002 \\
\hline $\begin{array}{l}\text { No differentiation } \\
\text { between C-M junction }\end{array}$ & 0 & $3(0.4 \%)$ & \\
\hline \multirow[t]{2}{*}{ Normal } & 0 & $1(0.1 \%)$ & \\
\hline & $33(36.7 \%)$ & $489(59.1 \%)$ & $<0.001$ \\
\hline
\end{tabular}

The laboratory examination results are expressed as mean \pm standard deviation.

DMSA (+), the existence of cortical defects on DMSA scan.

Abbreviations: DMSA, dimercaptosuccinic acid; N, number of patients; APD, anterioposterior diameter; C-M, corticomedullary, $P<0.05$. among children with a febrile UTI, acquired renal scarring developes only in some children with cortical defects on their DMSA scan, regardless of the presence of VUR.

A DMSA renal scan or computed tomography should be performed to prevent missing renal scarring, but to perform a DMSA scan on all patients with their first febrile UTI is not acceptable due to the low benefits compared with the risks, such as radiation exposure.

Trying to predict cortical defects on an acute DMSA scan in children with a febrile UTI is challenging. Procalcitonin and neutrophil gelatinase-associated lipocalin are the best known parameters to predict the presence of cortical defects in children with a febrile $\mathrm{UTI}^{3,4}$, but the tests are expensive and are not used to diagnose acute pyelonephritis in the Korean health care system because these parameters do not better predict the presence of cortical defects than CRP, WBC, or erythrocyte sedimentation rate in consideration of the cost to benefit ratio. Therefore, additional parameters to predict cortical defects in children with a febrile UTI are needed to more accurately predict pyelonephritis with cortical defects.

US is usually recommended in children with their first episode of febrile UTI. In our previous study ${ }^{1)}$, US had low SS to predict positive DMSA scan results. However, Mohkam et al. ${ }^{5)}$ reported that US is a sensitive method to detect renal cortical defects in patients with pyelonephritic [SS 69.2\% (95\% CI 62.1-72.6), SP 89.3\% (95\% CI 80.2-94.9), positive predictive value (PPV) 65.5\% (95\% CI 60.5-70.9) and NPV 81.5\% (95\% CI 75.9-84.7)]. A few studies have suggested results similar with this study ${ }^{6,7)}$. However, these studies did not specify what US findings predicted cortical defects on a DMSA scan. Furthermore, other reports have indicated that US is not sensitive to detect renal cortical defects in children with a febrile $\mathrm{UTI}^{8-10)}$. This study suggests that only some US findings could predict renal cortical defects (Table 2).

If the difference in both renal lengths on US was $\geq 10$ $\mathrm{mm}$, the SS, SP, PPV, and NPV to predict cortical defects on the DMSA scan were $10.6 \%$ (95\% CI 7.9-13.8), 98.5\% (95\% CI 96.9-99.4), 87\% (95\% CI 75.4-93.6), and 53.5\% (95 $\%$ CI 52.7-54.4), respectively. In cases with a renal length discrepancy $\leq 10 \mathrm{~mm}$, mean renal length of both kidneys in children with a positive DMSA scan result was larger than in children with a negative DMSA scan result (normal), 
even after adjusting for age between the two groups, and when there was no difference between renal sizes (Table 1).

In this study, a significant positive correlation was detected between the renal size discrepancy on US and the difference in RRU on the DMSA scans $(\mathrm{r}=0.21813, P<0.001)$ (Table 3). However, if renal scarring was defined when the difference in RRU on the DMSA scans were $\geq 20 \%$, there were no significant US findings for detecting renal scarring. Therefore, to prevent missing the children with congenital renal scarring, a DMSA scan should be performed in children with a recurrent febrile UTI.

There has been known that there is no clear tool to discriminate the differences between congenital scar and acquired scar. However, there exist differences between congenital scar and cortical defects due to acute inflammation on DMSA scan. Congenital scar includes absent tracer localization that deforms the renal contour and generalized decreased tracer. Hypoplastic kidney belongs to congenital scar. This study population included only children with the first episode of acute pyelonephritis, and 805 children of them were less than 12 month-old. Therefore, chronic defects due to repeated infection except congenital scarring could be excluded when DMSA scans were interpreted.

In conclusion, both renal size discrepancy on US in children with their first episode of febrile UTI was a useful tool to predict cortical detects on a DMSA scan. However, no US findings could detect all children with congenital renal scarring.

\section{Disclosure}

All the authors declared no competing interests.

\section{ORCID}

Jun Ho Lee -naesusana@gmail.com Yoowon Kwon -https://orcid.org/0000-0002-9249-7493 Bo kyeong Jin-https://orcid.org/0000-0002-9080-2001
Seonkyeong Rhie-https://orcid.org/0000-0003-33718310

\section{Patient consent}

This study was approved by the institutional review board (IRB), and the consent was waived due to the nature of the retrospective study [IRB number 2018-07-063].

\section{References}

1. Lee JH, Kim MK, Park SE. Is a routine voiding cystourethrogram necessary in children after the first febrile urinary tract infection. Acta Paediatr 2012;101:e105-9.

2. Shaikh N, Spingarn RB, Hum SW. Dimercaptosuccinic acid scan or ultrasound in screening for vesicoureteral reflux among children with urinary tract infections. Cochrane Database Syst Rev. 2016 Jul 5;7:CD010657. Doi:10.1002/14651858.CD010657.pub2.

3. Leroy S, Gervaix A. Procalcitonin: a key marker in children with urinary tract infection. Adv Urol 2011;2011:397618.doi:10.1155/ 2011/397618. Epub 2011 Jan 17.

4. Kim BK, Yim HE, Yoo KH. Plasma neutrophil gelatinase-associated lipocalin: a marker of acute pyelonephritis in children. Pediatr Nephrol 2017;32:477-84.

5. Mohkam M, Jahdavi C, Arad B, Moein HR, Tabar RV, Olyaie M, et al. The sensitivity of ultrasonography in detecting renal cortical defects in pyelonephritic patients with or without vesicoureteral reflux. J Ped Nephrol 2013;1:28-31.

6. Barrt BP, Hall N, Cornford E, Broderick NJ, Somers JM, Rose DH. Improved ultrasound detection of renal scarring in children following urinary tract infection. Clin Radiol 1998;53:747-51.

7. Bjorgvinsson E, Majd M, Egglil KD. Diagnosis of acute pyelonephritis in children: Comparison of sonography and 99mTc-DMSA scintigraphy. AJR 1991;157:539-43.

8. Levocat MP, Granjon D, Allard D, Gay C. Imaging of pyelonephritis. Pediatr Radiol 1997;27:159-65.

9. Moorthy I, Wheat D, Gordon I. Ultrasonography in the evaluation of renal scarring using DMSA scan as the gold standard. Pediatr Nephrol 2004;19:153-6.

10. Scherz HC, Downs TM, Caesar R. The selective use of dimercaptosuccinic acid renal scans in children with vesicoureteral reflux. J Urol 1994;152:628-31. 